doi: $10.2306 /$ scienceasia1513-1874.2013.39.019

\title{
Thunbergia laurifolia leaf extract mitigates cadmium toxicity in rats
}

\author{
Werawan Ruangyuttikarn $^{\mathrm{a}, *}$, Ploypailin Chattaviriya ${ }^{\mathrm{a}}$, Nattita Morkmek $^{\mathrm{a}}$, Sirirat Chuncharunee ${ }^{\mathrm{b}}$, \\ Nirush Lertprasertsuke ${ }^{c}$ \\ a Division of Toxicology, Department of Forensic Medicine, Faculty of Medicine, Chiang Mai University, \\ Thailand \\ b Department of Chemistry, Faculty of Science, Chiang Mai University, Thailand \\ c Department of Pathology, Faculty of Medicine, Chiang Mai University, Thailand
}

*Corresponding author, e-mail: ruangyuttikarn@gmail.com

Received 18 Jul 2012

Accepted 27 Nov 2012

\begin{abstract}
Thunbergia laurifolia (TL) is a medicinal herb traditionally used in Thailand for centuries as an antidote for several poisons. To test whether the TL could mitigate toxicity of cadmium, we subjected Wistar rats pre-fed with and without crude or partially purified extract of the TL to cadmium challenge. Physiopathology of the rats and histopathological examination of the kidney and liver revealed that pre-fed rats with the TL reduced toxicity signs and organ damages caused by cadmium. The extracts did not alter the cadmium concentrations in blood or urine. Nuclear magnetic resonance spectroscopy detected aromatic and glycoside compounds in the TL extract which may have been the mechanism of the observed mitigation effects of the extract. This finding suggests that TL herbal tea may be useful in humans with unavoidable exposure to environmental cadmium.
\end{abstract}

KEYWORDS: leaf extract, herbal tea, traditional medicine

\section{INTRODUCTION}

Thunbergia laurifolia Lindl. (TL), named 'rang jeud' in Thai, is a shrub with small, oblong or ovate leaves and bluish-purple flowers. The plant is traditionally used in Thailand for centuries as an antidote for several poisons and drug overdose, delivered as herbal tea prepared from the leaves. Previous studies reported that it mitigates the toxic effects of insecticide such as parathion ${ }^{1,2}$ and herbicide such as paraquat ${ }^{3}$. The reports also indicate the TL protects ethanol hepatotoxicity ${ }^{4}$, stimulates brain similar to addictive drugs ${ }^{5}$, reduces blood glucose in diabetic rats ${ }^{6}$, and has antimutagenic ${ }^{7}$ and anti-oxidant effects ${ }^{8}$. In addition, TL extract has successfully alleviated lead poisoning in rats ${ }^{9}$. Studies of the toxicity of the TL itself found that aqueous extract of the TL leaves in the massive single dose was non-toxic in rats ${ }^{10}$ and had no cytotoxicity ${ }^{8}$. However, there are no reports of the effect of the TL leaf extract in possibly reducing or preventing systemic toxicity induced by cadmium.

Cadmium $(\mathrm{Cd})$ is a toxic metal in the earth crust which always occurs in physical admixture with zinc $^{11}$. Thus it is often an environmental pollutant that occurs as a by-product of zinc, lead and copper extrac- tion from industry or mining plants ${ }^{11}$. Environmental Cd pollution has been found worldwide ${ }^{12-14}$ and in Thailand is particularly extensive in Mae Sot district of Tak province ${ }^{15}$, where high Cd concentrations were reported in the urine of residents ${ }^{16}$. The source of $\mathrm{Cd}$ is believed to be a zinc-mine area, located upstream of creeks and canals for irrigation, where the zinc mine had been operated for more than 20 years ${ }^{17}$.

Our previous studies showed that people living in this Cd-contaminated area suffered renal dysfunction $^{18}$. In the same population, the prevalence of chronic diseases such as hypertension, kidney stones, diabetes, and anaemia were also found to correlate positively with $\mathrm{Cd}$ levels in blood and urine ${ }^{19-21}$. A recent five-year study (2005-2010) of persons with chronic $\mathrm{Cd}$ exposure showed that toxic effects may continue even after the $\mathrm{Cd}$ exposure is reduced ${ }^{22}$. The aim of this study was to investigate in a rat model whether TL leaf extract could reduce physioand histo-pathologies of chronic Cd toxicity with the hope of potential use of the herb in humans. The extract was also analysed by the proton nuclear magnetic resonance spectroscopy ( ${ }^{1} \mathrm{H}$ NMR) to identify the active ingredients. 


\section{MATERIALS AND METHODS}

\section{Preparation of crude extract}

Mature leaves of TL were collected in July and October 2009 from Ob Khan National Park, Hangdong District, Chiang Mai Province, Thailand. Taxonomic identification was confirmed by expert examination at the Queen Sirikit Botanic Garden, Mae Rim District, Chiang Mai Province. The leaves were washed with tap water, air dried, ground to a fine powder, and stored in an amber glass bottle at room temperature. A TL herbal tea was prepared by soaking the leaf powder in hot water $\left(90-100^{\circ} \mathrm{C}, 1: 10 \mathrm{w} / \mathrm{v}\right)$ for $1 \mathrm{~h}$, then filtering through three layers of gauze followed by Whatman No. 4 filter paper. The filtrate was lyophilized and stored in a desiccator at $4{ }^{\circ} \mathrm{C}$ for use as crude extract.

\section{Preparation of purified extract}

Two milligrams of the lyophilized powder of crude extract was dissolved in a small amount of $95 \%$ ethanol before loaded onto the column chromatography $(50 \mathrm{~mm}$ diameter, $50 \mathrm{~cm}$ height) packed with silica gel. Eight hundred millilitres of the mixture of n-hexane and ethyl acetate at the ratio of 80:20, $60: 40,40: 60,20: 80$, or 0:100 were added to elute the extract, respectively, followed by a mixture of ethyl acetate and methanol at the same ratio. Eighteen fractions were collected and evaporated with rotary evaporator (RotaVapor, Buchi, Japan) and analysed on thin layer chromatography. Selected fractions were then dissolved in $\mathrm{D}_{2} \mathrm{O}$ solution and analysed with proton nuclear magnetic resonance spectroscopy (Bruker AVANCE-400 MHz, Rheinstetten, Germany). Fractions with the same NMR spectra were pooled, lyophilized and stored in a desiccator at $4{ }^{\circ} \mathrm{C}$ for use as purified extract.

\section{Animals}

Male Wistar rats (Rattus norvegicus), weighing between 200 and $250 \mathrm{~g}$, were obtained from the animal house of the faculty of medicine, Chiang Mai University. Before each experiment they were acclimatized for one week under controlled experimental conditions of temperature $\left(25 \pm 2{ }^{\circ} \mathrm{C}\right)$, light $(12 \mathrm{~h}$ light/dark cycle), and relative humidity $(50 \% \pm 10 \%)$. They had free access to drinking water and standard rodent feed pellets throughout the experiment. The study protocol was approved by the Animal Ethics Committee of the Faculty of Medicine, Chiang Mai University (Approved protocol No16/2010, August 10th, 2012).

\section{Administration of TL extract to animals}

Both crude and purified extract of the TL were prepared in drinking-water. The dose for a rat, approximated a human dosage of 3 cups $(250 \mathrm{ml} / \mathrm{cup})$ of TL tea per day, was $0.1 \mathrm{mg} / \mathrm{ml}$ of TL leaf lyophilized powder of crude extract or $0.02 \mathrm{mg} / \mathrm{ml}$ of the purified residue. It was supplied in $120 \mathrm{ml}$ of distilled water, which was the daily drinking-water ration for each rat.

\section{Animal treatment}

Sixteen rats were separated into 3 groups. Six rats in group 1 were pre-fed with the crude extract in drinking water from day 1 to day 20 prior to $\mathrm{Cd}$ challenge by administration of $\mathrm{CdCl}_{2}$ solution $(1.0 \mathrm{mg} / \mathrm{kg}$ per day) in isotonic saline, subcutaneously, on day 21 to day 40. During Cd challenge, the rats were also fed with the extract throughout the experiment. Five rats in group 2 were performed similarly to group 1 except pre-feeding and feeding with the purified extract instead of crude extract. Rats $(n=5)$ in group 3 were our positive control which were treated with $\mathrm{Cd}$ only. There were more rats used as negative control, fed with water $(n=3)$ and injected with normal saline solution $(n=3)$ instead of $\mathrm{Cd}$ on day 21 to day 40 . They were sacrificed on day 41 and kidneys and livers were weighted. Tissue histopathological examination was performed in the same way as for the treated rats but urine and blood were not collected.

\section{Physiopathology}

The appearance and behaviour of the rats were observed twice a day. The body weight and water consumption of each rat were measured daily. Twenty $4 \mathrm{~h}$ urine samples were collected from each rat using metabolic cages for $\mathrm{Cd}$ concentration analysis. The urine was collected before treatment (day 0), during treatment (day 20), and at the end of experiment (day 40). On day 41, all rats were anaesthetized with sodium phenobarbital and blood was taken via the jugular vessel. The kidney and liver were perfused with normal saline solution and removed, weighed and kept in neutral-buffered formalin solution for histopathological examination. Dead rats during experiment were taken the kidney and liver off, weighted and kept for histopathological examination, but urine and blood could not be collected.

\section{Histopathology}

The livers and kidneys of all rats were dissected and fixed in $10 \%$ neutral-buffered formalin. The tissues were embedded in paraffin blocks, cut in a section of $4 \mu \mathrm{m}$ thickness, stained with haematoxylin-eosin, 
and randomly selected to examine under a light microscope.

The degree of kidney damage was graded from score 0 to +3 . Score 0 means absence of glomerular swelling, proximal tubular degeneration and interstitial inflammation, +1 means mild degree or randomly observed of the damage less than $10 \%,+2$ means moderate degree or scattered damage in between $10 \%$ to $50 \%$ and +3 means profound degree of damage more than $50 \%$ of the tissue found on one selected slide. The degree of liver damage was similarly graded from 0 to +3 for hepatocytic necrosis, hepatopyknotic nuclei and dilation of the hepatic sinusoid.

\section{Quantification of blood and urinary cadmium, and urinary creatinine}

Blood and urinary $\mathrm{Cd}$ concentrations were quantified by a graphite furnace AAS (GFAAS) with Zeeman background correction (Varian, SpectraA800Z, Australia) using 5\% monobasic ammonium phosphate as a modifier. Blood samples were digested in $5 \% \mathrm{HNO}_{3}$ solution with a ratio of $1: 3(\mathrm{v} / \mathrm{v})$, then mixed, and centrifuged after standing for an hour. The supernatant was removed for analysis. Urine samples were diluted in $0.1 \% \mathrm{HNO}_{3}$ solution with a ratio of $1: 1(\mathrm{v} / \mathrm{v})$ before analysis by GFAAS. Urinary creatinine levels were measured based on the Jaffe reaction ${ }^{23}$. Cadmium in urine was quantified per gram of creatinine.

\section{Identification of the leaf extract by nuclear magnetic resonance}

Chemical constituents of the crude TL leaf extract and selected fractions were identified and characterized by the ${ }^{1} \mathrm{H}$ NMR with water suppression technique ${ }^{24}$. NMR spectra were obtained over an $8278 \mathrm{~Hz}$ sweep width and digitized with $60 \mathrm{k}$ complex data points. There were 256 and 16 scans, respectively. Spectra were primarily processed in the frequency domain using XWINNMR (Bruker GmBH, Rheinstetten, Germany). The free induction decays were multiplied by an exponential function corresponding to $0.3 \mathrm{~Hz}$ line broadening.

\section{Chemicals and reagents}

All solvents used in the purification of the extract were distilled before use. All glassware was cleaned with acetone to prevent contamination. Solvents used in $\mathrm{Cd}$ quantification were of atomic absorption spectroscopy (AAS) grade. The certified Cd standard solution was purchased from Sigma-Aldrich (Germany). All plastic ware and glassware used in $\mathrm{Cd}$ analysis were cleaned with $20 \% \mathrm{HNO}_{3}$ to prevent metallic contamination.
All other chemicals and reagents were analytical grade.

\section{Statistical analysis}

Data were expressed as mean \pm standard error of mean. The statistical significance was evaluated by one-way ANOVA using SPSS version 16.0. Values were considered statistically significant when $p<$ 0.05 .

\section{RESULTS AND DISCUSSION}

\section{TL pre-feeding reduced physiopathology of $\mathrm{Cd}$ toxicity}

Rats with Cd challenge showed abnormal physical appearances and behavioural responses such as fear of touch, loss of hair, hunched back, swollen face, and scarring or muscle necrosis at the injection site. Out of 5 rats in positive control group with $\mathrm{Cd}$ challenge, one died on day 32 and one died on day 33. No rat died in the in crude and purified TL extract prefeeding groups. The abnormal appearances and types of behaviour caused by $\mathrm{Cd}$ toxicity were seen milder or absence in rats pre-fed with the TL crude and purified extracts.

The rat body weight increased slowly since the first day of treatments (Fig. 1) except on day 2 after starting experiment and day 21 after $\mathrm{Cd}$ injection which it dropped slightly to started risen up gradually from day 3 to day 20. After $\mathrm{Cd}$ challenge the average weights of rats pre-fed with TL extract gradually increased significantly different from the body weights of rats with no TL pre-feeding. Both crude and purified TL extract showed no difference but significant difference from rats treated with $\mathrm{Cd}$

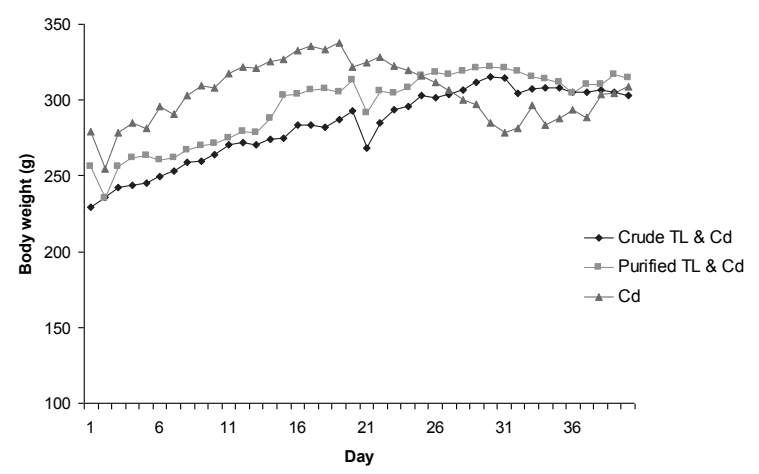

Fig. 1 Mean of body weights of rats pre-fed with crude $(n=$ $6)$ or purified TL $(n=5)$ extract before Cd challenge with $\mathrm{CdCl}_{2}$ compared to body weights of rats in Cd challenge group $(n=5)$. 
Table 1 Kidney and liver weight.

\begin{tabular}{lccc}
\hline Study & \multicolumn{2}{c}{ Kidney $(\mathrm{g})$} & Liver $(\mathrm{g})$ \\
\cline { 2 - 3 } group & Right & Left & \\
\hline 1. & $1.00 \pm 0.08^{*}$ & $0.97 \pm 0.05^{* *}$ & $12.6 \pm 0.6^{\#}$ \\
2. & $1.38 \pm 0.05$ & $1.37 \pm 0.05$ & $14.9 \pm 0.4$ \\
3. & $1.33 \pm 0.06$ & $1.30 \pm 0.07$ & $12.9 \pm 1.4$ \\
4. & $1.13 \pm 0.13$ & $1.17 \pm 0.10$ & $10.1 \pm 0.4$ \\
\hline
\end{tabular}

Study groups: 1 . Crude TL \& Cd challenge $(n=6)$; 2. Purified TL \& Cd challenge $(n=5) ; 3$. Cd challenge $(n=5)$; 4. Normal saline solution $(n=3)$.

${ }^{*} p<0.05,{ }^{* *} p<0.01$ significantly different from groups 2 and $3 ;{ }^{\#} p<0.05$ significantly different from group 2 only. Data are mean \pm standard error of mean.

alone. Because two presumably thin rats in Cd treatment alone died, there were three rats that survived which made the average weight of rats in this group increased unexpectedly after day 33 .

Rats pre-fed with the TL consumed more water than rats which were not received either the crude or purified TL extracts (data not shown). We also noticed that rats pre-fed with the TL ate more food pellets during the $\mathrm{Cd}$ treatment period than rats which did not receive any TL extract.

The mean weight of right and left kidneys of the rats pre-fed with crude TL were significantly different from that of rats pre-fed either with purified $\mathrm{TL}$ or treated with $\mathrm{Cd}$ only or untreated rats (given normal saline solution) (Table 1). However, the liver weight of rats pre-fed with crude TL was significantly different from that of rats in group 2, but not in that of groups 3 and 4 .

\section{Histopathology}

Histology of the normal kidney without damages is shown in Fig. 2a in comparison to the kidney with glomerular swelling, degenerative tubules, and interstitial inflammation in Cd treatment only (Fig. 2b). The kidney of pre-fed TL rat showed histology simi-
Table 2 Number of rats with and without kidney damages.

\begin{tabular}{|c|c|c|c|c|c|c|c|c|c|c|c|c|}
\hline \multirow{3}{*}{$\begin{array}{l}\text { Study } \\
\text { group }\end{array}$} & \multicolumn{12}{|c|}{ Kidney } \\
\hline & \multicolumn{4}{|c|}{$\begin{array}{l}\text { Glomerular } \\
\text { swelling }\end{array}$} & \multicolumn{4}{|c|}{$\begin{array}{c}\text { Proximal tubular } \\
\text { degeneration }\end{array}$} & \multicolumn{4}{|c|}{$\begin{array}{l}\text { Interstitial } \\
\text { inflammation }\end{array}$} \\
\hline & +3 & +2 & +1 & 0 & +3 & +2 & +1 & 0 & +3 & +2 & +1 & 0 \\
\hline 1. & - & - & 4 & 2 & - & - & - & 6 & - & - & - & 6 \\
\hline 2. & 2 & 3 & - & - & 2 & 2 & 1 & - & 1 & 1 & 3 & - \\
\hline 3. & 4 & - & 1 & - & 3 & 1 & 1 & - & 4 & - & 1 & - \\
\hline 4. & - & - & - & 3 & - & - & - & 3 & - & - & - & 3 \\
\hline
\end{tabular}

Grading score: $+3=$ profound damage or diffuse damage to more than $50 \%$ of the tissue; $+2=$ moderate damage or damage scattered over less than $50 \%$ of tissue; $+1=$ mild damage or random in less than $10 \%$ of the tissue; $0=$ no damage. Study groups as in Table 1.

larly to normal kidney (Fig. 2c). Grading of the kidney damage was shown by grading score from +3 to 0 (Table 2). Kidneys of almost all rats injected with $\mathrm{CdCl}_{2}$ alone had profound damages of the kidney but most rats in TL pre-feeding found less damage. Only 4 rats in crude TL pre-feeding showed mild glomerular swelling while others were similar to normal kidney. Some rats in purified TL pre-feeding showed kidney damages more than rats pre-fed with crude extract.

Both crude and purified TL could protect all damages caused by $\mathrm{Cd}$ to the livers. Histology of normal liver shown in Fig. 3a compared to the liver of a rat with $\mathrm{Cd}$ challenge, no rats pre-fed crude $\mathrm{TL}$ showing severe toxicity of peripheral necrosis, small hepatocytic cords bearing vacuolated cytoplasm, pyknotic nuclei, chromatin condensation, and sinusoidal widening (Fig. 3b). The liver of rat pre-fed crude TL and $\mathrm{Cd}$ challenge with hepatic tissue architecture similar to normal liver w (Fig. 3c). Grading of the liver damage was shown in Table 3 in which both crude and purified TL could protect all damages caused by $\mathrm{Cd}$ to the livers.

Human are commonly exposed to Cd through the ingestion of Cd-contaminated food or water ${ }^{11,25,26}$,
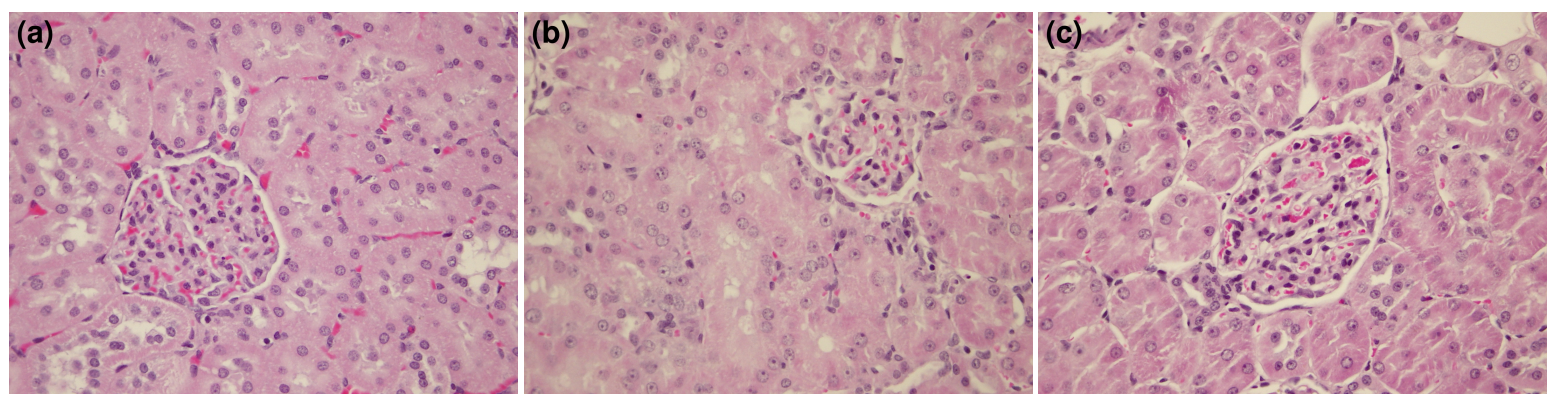

Fig. 2 Histology of rat's kidney $(400 \times)$. (a) Normal kidney, (b) Cd challenge, (c) Prefed TL \& Cd challenge. 

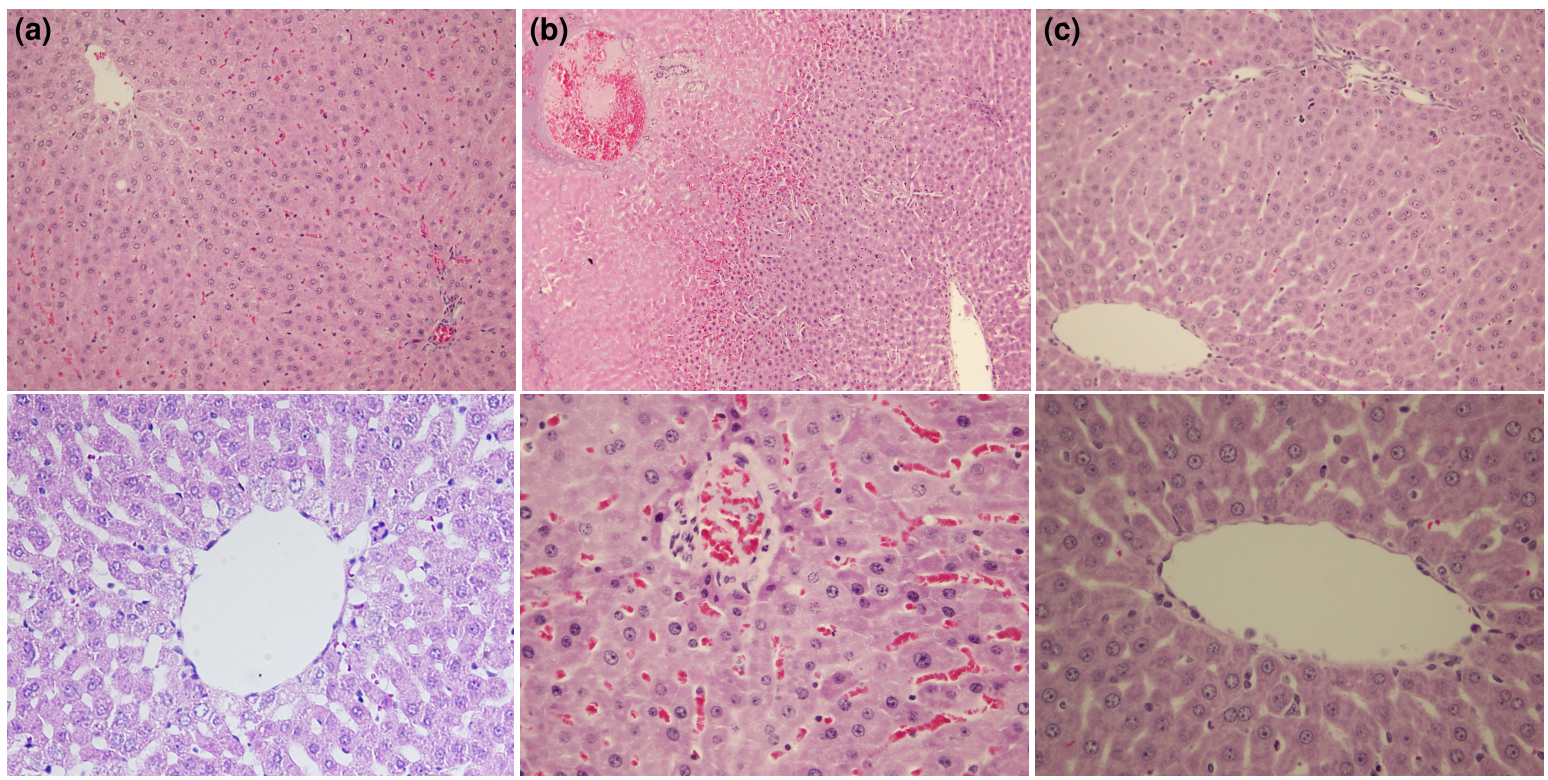

Fig. 3 Histology of rat's liver. Top panels: $100 \times$; lower panels: $400 \times$. (a) Normal liver, (b) Cd challenge, (c) Prefed TL \& Cd challenge.

Table 3 Number of rats with and without liver damages.

\begin{tabular}{|c|c|c|c|c|c|c|c|c|c|c|c|c|}
\hline \multirow{3}{*}{$\begin{array}{l}\text { Study } \\
\text { group }\end{array}$} & \multicolumn{12}{|c|}{ Liver } \\
\hline & \multicolumn{4}{|c|}{$\begin{array}{l}\text { Hepatocytic } \\
\text { necrosis }\end{array}$} & \multicolumn{4}{|c|}{$\begin{array}{c}\text { Hepatocytic } \\
\text { pyknotic nuclei }\end{array}$} & \multicolumn{4}{|c|}{$\begin{array}{l}\text { Dilation of } \\
\text { sinusoid }\end{array}$} \\
\hline & +3 & +2 & +1 & 0 & +3 & +2 & +1 & 0 & +3 & +2 & +1 & 0 \\
\hline 1. & - & - & - & 6 & - & - & - & - & - & - & 1 & 5 \\
\hline 2. & - & - & & 5 & 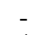 & 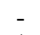 & . & 5 & 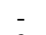 & - & 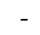 & 5 \\
\hline 3. & 5 & - & - & - & 4 & 1 & - & - & 3 & - & - & 2 \\
\hline 4. & - & - & - & 3 & - & - & - & 3 & - & - & - & 3 \\
\hline
\end{tabular}

Grading score as in Table 2. Study groups as in Table 1.

like in our case via rice which is a Thai staple food ${ }^{27}$. With chronic oral exposure of $\mathrm{Cd}$ through food, $\mathrm{Cd}$ is absorbed from gastrointestinal tract and transported via the portal circulation to the liver where it is efficiently taken up by hepatocytes ${ }^{25}$. In the hepatocytes $\mathrm{Cd}$ induced the synthesis of metallothionein, which binds tightly with $\mathrm{Cd}$ to be non-toxic compound in the liver cells. Then it will be transported to the kidney, passed through glomerular and re-absorbed back to proximal tubular cells where the $\mathrm{Cd}$-metallothionein were degraded, resulting in the release of $\mathrm{Cd}$ within the cell and alter cells function. Therefore, the protective effects of the liver damage from Cd toxicity by the TL leaf extract may not result from the real protective mechanism by TL but rather than the toxic effects of $\mathrm{Cd}$ is not as prominent to the liver compared to the kidney.
Table 4 Blood and urinary $\mathrm{Cd}$ of the rats.

\begin{tabular}{|c|c|c|c|c|}
\hline \multirow{2}{*}{$\begin{array}{l}\text { Study } \\
\text { group }\end{array}$} & \multicolumn{3}{|c|}{$\mathrm{UCd}(\mu \mathrm{g} / \mathrm{g} \mathrm{Cr})$} & $\mathrm{BCd}(\mu \mathrm{g} / \mathrm{l})$ \\
\hline & Day 0 & Day 20 & Day 40 & Day 40 \\
\hline 1. & $35 \pm 12$ & $20.4 \pm 6.9$ & $71000 \pm 23000$ & $5090 \pm 530$ \\
\hline 2. & $\begin{array}{l}37 \pm 11 \\
31 \pm 16\end{array}$ & $\begin{array}{l}17.8 \pm 4.1 \\
23.2 \pm 6.4\end{array}$ & $\begin{array}{l}70500 \pm 3200 \\
79000 \pm 25000\end{array}$ & $\begin{array}{l}5250 \pm 310 \\
5400+620\end{array}$ \\
\hline
\end{tabular}

$\mathrm{BCd}=$ blood cadmium, $\mathrm{UCd}=$ urinary cadmium, $\mathrm{Cr}=$ creatinine, Day $0=$ before treatment, values represent mean \pm standard error of mean.

\section{Cadmium concentrations in blood and urine}

The Cd concentrations in urine on day 0 and day 20 were not significantly different among all experimented rats before Cd challenge (Table 4). However, the $\mathrm{Cd}$ levels were increased significantly in all rats on day 40 demonstrated of $\mathrm{Cd}$ accumulation in the body of rats after $\mathrm{Cd}$ challenge. Both crude and purified TL extract did not alter the concentration of $\mathrm{Cd}$ in both blood and urine even though the extract could reduce kidney and liver damages.

\section{Constituents of the TL leaf extract}

Aromatic proton signals at the chemical shift $(\delta)$ between 9.6 and $6.2 \mathrm{ppm}$ and glycoside protons between $\delta$ 4.5-2.8 ppm were found in both crude and purified TL (Fig. 4). Crude extract seems to have more signal than the purified extract. TL extract from the leaves collected in July and October showed nonsignificantly different signals (data not shown). 


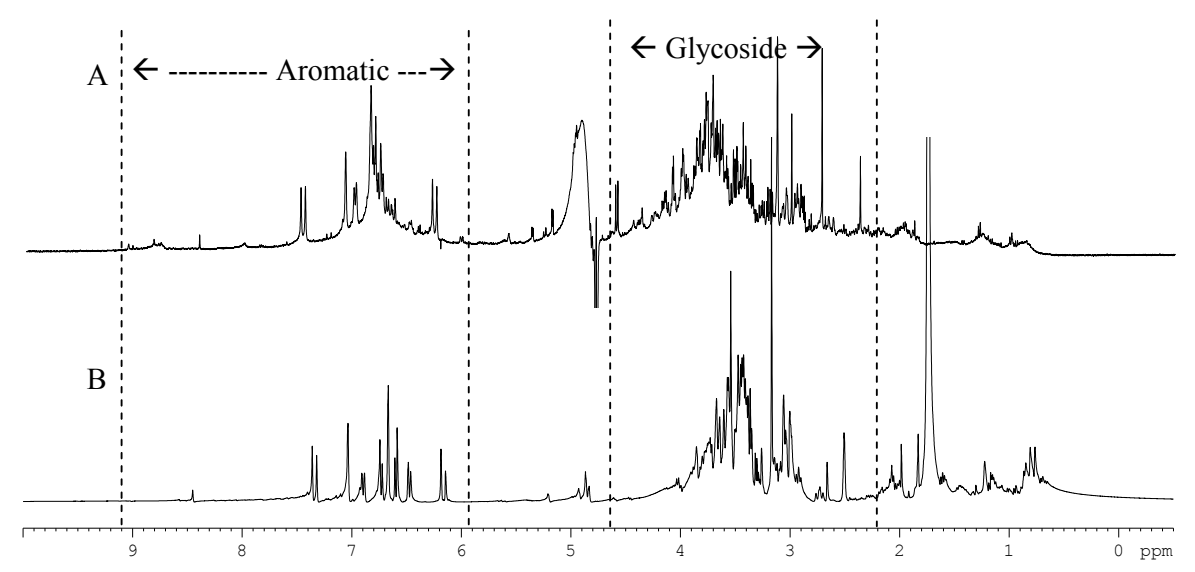

Fig. 4 NMR spectra of the crude extract (A) and partially purified extract (B).

Oonsivilai et al ${ }^{28}$ and Kanchanapoom et al ${ }^{29}$ have reported that the phenolic content of the TL leaf aqueous extract (2434 $\mathrm{mg}$ GAE/100 g) was higher than ethanol extract (565 mg GAE/100 g), and acetone (142 mg GAE/100 g) and that the aqueous extract had the highest antioxidant activity. Those findings have supported the popularity of the TL plant as a therapeutic herbal tea. In our earlier study ${ }^{30}$, we found that feeding TL leaf extract in massive dose via oral route before and after $\mathrm{Cd}$ administration did not alleviate $\mathrm{Cd}$ toxicity. Therefore, the method of providing the TL leaf extract in drinking water before the $\mathrm{Cd}$ administration was more suitable to help increase the protective effect of the TL leaf treatment.

Oonsivilai et al $^{31}$ also reported the presence of apigenin and apigenin glucosides as well as phenolic acids such as caffeic acid, gallic acid and protocatechuic acid in the water extract of the plant. The protective effects of the TL leaf extract against $\mathrm{Cd}$ toxicity found in our study were presumably due to the integrated effect of numerous ingredients in the crude extract, not due to the few found in the partially purified extract.

\section{CONCLUSIONS}

This study has demonstrated that aqueous TL leaf extract supplied to rats in drinking water significantly reduces the systemic cadmium toxicity and protect kidney and liver tissues from structural damage. The crude TL extract was more effective than the partially purified extract, presumably because of the higher concentrations of phenolic and glycoside compounds. However, the extract did not reduce the levels of $\mathrm{Cd}$ in blood and urine of the rats. Eventually, clinical trial in human will be necessary to determine whether the Thai traditional medicine remedy can benefit people suffering with chronic diseases after dietary exposure to high levels of cadmium. The results from this study provide further impetus to identify the active ingredients in TL extract herbal tea which reduce systemic toxicity from cadmium especially to the kidney and their mode of action.

Acknowledgements: The authors thank Dr Weerachai Na Nakorn at the Queen Sirikit Botanic Garden for his kind identification of the plant taxonomy. Thanks to Drs Peter R. Hawkins and Bruce G. Weniger for their valuable comments and help proof reading the manuscript. The study was supported by the Faculty of Medicine Endowment Fund, Faculty of Medicine, Chiang Mai University.

\section{REFERENCES}

1. Tejasen P, Thongthapp C (1980) The study of the insecticide antitoxicity of Thunbergia laurifolia Linn. Chiang Mai Med Bull 19, 105-14.

2. Ussanawarong S, Thesiri T (2000) Effect of Thunbergia Laurifolia Linn. on detoxication of parathion in rat. KKU Res J 6, 3-13.

3. Ussanawarong $\mathrm{S}$, Thesiri T, Mahakunakorn T, Parasupattana S (2001) Effect of Thunbergia Laurifolia Linn. on detoxication of paraquat. KKU Res $J$ 5, 11-7.

4. Pramyothin P, Chirdchupunsare H, Rungsipipat A, Chaichantipyuth C (2005) Hepatoprotective activity of Thunbergia laurifolia Linn. extract in rats treated with ethanol: In vitro and in vivo studies. J Ethnopharmacol 102, 408-11.

5. Thongsaard W, Marsden CA, Morris P, Prior M, Shah YB (2005) Effect of Thunbergia laurifolia, a Thai natural product used to treat drug addiction, on cerebral activity detected by functional magnetic resonance imaging in the rat. Psychopharmacology 180, 1-9.

6. Aritajat S, Wutteerapol S, Saenphet K (2004) Antidiabetic effect of Thunbergia laurifolia Linn. aqueous 
extract. Southeast Asian J Trop Med Publ Health 35, 53-8.

7. Saenphet K, Kantaoop P, Saenphet S, Aritajat S (2005) Mutagenicity of Pueraria mirifica Airy Shaw \& Suvatabandhu and antimutagenicity of Thunbergia laurifolia Linn. Southeast Asian J Trop Med Publ Health 36, 238-41.

8. Chan EWC, Lim YY (2006) Antioxidant activity of Thunbergia laurifolia tea. J Trop Forest Sci 18, 130-6.

9. Tangpong J, Satarug S (2010) Alleviation of lead poisoning in the brain with aqueous leaf extract of the Thunbergia laurifolia (Linn.). Toxicol Lett 198, 83-8.

10. Wisitpongpan W, Ruangyuttikarn W, Rujjanavet C (2003) Toxicity tests of Rang Jert (Thunbergia laurifolia Linn.) leaves aqueous extracts in rats. Thai $J$ Phytopharmacy 10, 23-36.

11. WHO/IPCS (1992) Cadmium. Environmental Health Criteria Document 134, IPCS. WHO, Geneva.

12. Kido T, Kobayashi E, Hayano M, Nogawa K, Tsuritani I, Nishijo M, Tabata M, Nakagawa H, Nuyts GD, DeBroe ME (1995) Significance of elevated urinary human intestinal alkaline phosphatase in Japanese people exposed to environmental cadmium. Toxicology $\mathbf{8 0}$, $49-54$.

13. Satarug S, Garrett SH, Sens MA, Sens DA (2010) Cadmium, environmental exposure, and health outcomes. Environ Health Perspect 118, 182-90.

14. Åkesson A, Lundh T, Vahter M, Bjellerup P, Lidfeldt J, Nerbrand C, Samsioe G, Stromberg U, Skerfving S (2005) Tubular and glomerular kidney effects in Swedish women with low environmental cadmium exposure. Environ Health Perspect 113, 1627-31.

15. Simmon RW, Pongsakul P, Saiyasitpanich D, Klinphoklap S (2005) Elevated levels of cadmium and zinc in paddy soils and elevated levels of cadmium in rice grain downstream of a zinc mineralized area in Thailand: implications for public health. Environ Geochem Health 27, 501-11.

16. SwaddiwudhipongW, Limpatanachote P, Mahasakpan P, Krintratun S, Padungtod C (2007) Cadmium-exposed population in Mae Sot District, Tak Province: 1. Prevalence of high urinary cadmium levels in the adults. J Med Assoc Thai 90, 143-8.

17. Tak Provincial Office (2005) Project development for solving the problem related to cadmium-contamination areas in Mae Sot District, Tak Province. Tak Provial Office Report.

18. Teeyakasem W, Nishijo M, Honda R, Satarug S, Swaddiwudhipong W, Ruangyuttikarn W (2007) Monitoring of cadmium toxicity in a Thai population with high-level environmental exposure. Toxicol Lett 169, 185-95.

19. Swaddiwudhipong W, Mahasakpan P, Limpatanachote P, Krintratun S (2010) Correlations of urinary cadmium with hypertension and diabetes in persons living in cadmium-contaminated villages in northwestern Thailand: A population study. Environ Res 110, 612-6.
20. Swaddiwudhipong W, Mahasakpan P, Limpatanachote P, Krintratun S (2011) An association between urinary cadmium and urinary stone disease in persons living in cadmium-contaminated villages in north western Thailand: A population study. Environ Res 111, 579-83.

21. Nambunmee K, Honda R, Nishijo M, Swaddiwudhipong W, Nakagawa H, Ruangyuttikarn W (2011) Bone cadmium exposure in Mae Sot population is associated with high anemia prevalence. Thai J Toxicol 26, 29-43.

22. Swaddiwudhipong W, Limpatanachote $P$, Mahasakpan P, Krintratun S, Punta B, Funkhiew T (2012) Progress in cadmium-related health effects in persons with high environmental exposure in northwestern Thailand: A five-year follow-up. Environ Res 112, 194-8.

23. Henry RJ (1964) Clinical Chemistry: Principles and Techniques. New York: Harper and Row.

24. Price WS (1999) Water signal suppression in NMR spectroscopy. Annu Rep Nmr Spectros 38, 289-354.

25. ATSDR (2008) Toxicological Profile for Cadmium. http://www.atsdr.cdc.gov/cercla/toxprofiles/tp5.html.

26. Jarup L, Akesson A (2009) current status of cadmium as an environmental health problem. Toxicol Appl Pharmacol 238, 201-8.

27. Honda R, Swaddiwudhipong W, Nishijo M, Mahasakpan P, Teeyakasem W, Ruangyuttikarn W, Satarug S, Padungtod C, Nakagawa H (2010) Cadmium induced renal dysfunction among residents of rice farming area downstream from a zinc-mineralized belt in Thailand. Toxicol Lett 198, 26-32.

28. Oonsivilai R, Cheng C, Bomser J, Ferruzzi GM, Ningsanond S (2007) Phytochemical profiling and phase II enzyme-inducing properties of Thunbergia laurifolia Lindl. (RC) extracts. J Ethnopharmacol 114, 300-6.

29. Kanchanapoom T, Kasai R, Yamasaki K (2002) Iridoid glucosides from Thunbergia laurifolia. Phytochemistry 60, 769-71.

30. Morkmek N, Lertprasertsuke N, Ruangyuttikarn W (2009) Establishment of a cadmium induced renal tubular damaged rat's model for investigating the effect of Thunbergia laurifolia Lindl. leaf extract on cadmium renal toxicity. Thai J Toxicol 24, 181.

31. Oonsivilai R, Ferruzzi MG, Ningsanond S (2008) Antioxidant activity and cytotoxicity of Rang Chuet (Thunbergia laurifolia Lindl.) extracts. Asian J Food Agro Ind 1, 116-28. 